\title{
Some Correlates of Risky User Behavior and ICT Security Awareness of Secondary School Students
}

Preliminary Communication

\author{
Ivana Borić Letica \\ Secondary School of Economics and Administration Osijek \\ Trg Sv. Trojstva 4 \\ Osijek, Croatia \\ ivanaboric9@yahoo.com
}

\begin{abstract}
The aim of the research was to examine some correlates of security awareness and risky behavior while using information technology. The sample consisted of 206 participants; i.e., 150 female and 56 male students from three secondary schools. The Users' Information Security Awareness Questionnaire, the Consciousness Subscale and the Self-Control Questionnaire were used. Results showed that there are statistically significant (low to moderate) correlations between some personality traits (self-control and consciousness) and time spent on the Internet, borrowing access data, different risky behaviors, computer maintenance and proper data storage. Adolescents show low levels of security awareness. Parents talk more about privacy and security risks with girls than with boys. Girls show more security awareness than boys but behave equally risky. Those with whom parents talk more about security risks show less risky behavior and more security awareness.
\end{abstract}

Keywords - ICT security awareness, parents, personality traits, risky user behavior

\section{INTRODUCTION}

The Internet is the basis of today's communication, but despite the benefits, it also poses a risk to users' security and privacy [1, 2]. Internet users are often unaware of the risks they face and act recklessly. Personal data needs to be properly protected, properly stored and should not be disclosed to other people. To reduce the potential risks, it is necessary to increase user awareness and knowledge of the security and privacy threats on the Internet [2].

\subsection{CORRELATES OF RISKY USER BEHAVIOR AND ICT SECURITY AWARENESS}

According to Livingstone and Bober [3], 44\% of children (11-16 years old) unwillingly discovered pornographic content online, $28 \%$ of children received pornographic e-mail from someone, $27 \%$ of children accidentally ended up in a place promoting violence, $46 \%$ of children provided personal information to someone online, $72 \%$ of children would give personal information to win the quiz award, $36 \%$ of children share online communication with people they only met online, and $9 \%$ of children met face to face with someone who they met and communicated only online. Other researchers also showed that children and adolescents show the lowest level of ICT security awareness and are exposed to the greatest online security risks; compared to adults, more secondary school students disclose their e-mail addresses and passwords, borrow personal data, and consider certain activities on the Internet more secure $[2,4]$. There are some gender differences in security awareness, too; men believe that computer communication is safer, and women believe that there is a greater likelihood that someone will steal their personal information [2]. Female students maintain computer systems more regularly than male students. However, there are no differences in risky user behavior regarding gender [4].

Besides age and gender, research shows that risky behavior on the Internet, such as cyberbullying or excessive Internet use, is often associated with different personality traits, such as conscientiousness, neuroticism, extraversion and self-control $[5,6,7]$. It is necessary to study in detail why people behave recklessly while using information technology since in the cases of disruption of security and privacy, the human factor has proved to be extremely important [8]. However, very little research has focused on which personality traits are related to risky user behavior, such as personal data disclosure, low computer system maintenance or low levels of ICT security awareness. 


\subsection{TIME ADOLESCENTS SPEND ON THE INTERNET AND PARENTAL MEDIATION}

An average child spends an hour a day on the Internet and adolescents spend two hours a day on the Internet [9]. The amount of time spent on the Internet is increasing; $73 \%$ of secondary school students contact their friends several times a day using the Internet, and $17 \%$ of secondary school students spend more than 5 hours a day on the Internet [10]. Almost $30 \%$ of children aged 11 to 16 experienced excessive Internet use once or more than once (negligence of school responsibilities, insomnia, etc.) [9]. Compared to girls, boys spend more time on the Internet [9]. Risky online behavior (cyberviolence, personal data disclosure, etc.) is associated with the amount of time spent online; the more time children and adolescents spend on the Internet, the more privacy and security risks they encounter [9].

Parents can influence their children's online behavior by supervising their online activities $[9,11]$. Livingstone and Helsper [11] distinguish between different types of parental media mediation:

- active mediation in which parents are present when a child is on the Internet or while using a media (discussing, providing advice and teaching);

- monitoring activities (parents monitor child's activity during and/or after the use of the Internet or some other media); and

- setting the technical limitations (blocking pages, setting the time limit, using filters, etc.).

One research [12] showed that $62 \%$ of 10 -year olds' parents restrict their child's Internet use and only 51\% of parents talk to their child about online risks. As children get older, parents are less involved in promoting their security awareness and think that children are exposed to less risk than they really are [9]. Risks that children face (personal data misuse, receiving disturbing messages or e-mails, cyberbullying, etc.) grow with children's age. Parental mediation is needed and can be successful in promoting ICT security awareness among children of any age [9]. Adolescents who are lonely and do not have parental or social support spend too much time on the Internet and are exposed to more security threats [13]. There is not enough research regarding parental influence on children's online behavior and ICT security awareness.

\subsection{THE AIM OF THE RESEARCH}

The aim of this research was to examine ICT security awareness and risky user behavior of secondary school students, to determine the correlations of these variables with personality traits (conscientiousness and self-control) and time spent on the Internet, and to examine whether there are differences therein regarding age, gender and parental mediation. The goal was to determine which group (in terms of age, gender, personality traits and type of parental mediation) is most vulnerable to online risks. Results can have practical purposes and reveal which population needs more education on ICT security.

The paper is organized as follows:

Section 1 gives Introduction and the aim of the research. The methodology (participants, instruments and procedure) is given in Section 2. Section 3 gives research results; descriptive results, correlations of research variables and t-test results. Conclusions are given in Section 4.

\section{METHODOLOGY}

The research was conducted in November 2018. The research procedure is described in detail below.

\subsection{PARTICIPANTS}

Participants were secondary school students $(\mathrm{N}=206)$ from the first $(\mathrm{N}=26)$, the second $(\mathrm{N}=40)$, the third $(\mathrm{N}=86)$ and the fourth grade $(\mathrm{N}=54)$ from three different vocational schools: Trade and Commercial School, Secondary School of Economics and Administration, and Technical School and High School of Natural Sciences Ruđer Bošković from Osijek. There were 27.2\% $(\mathrm{N}=56)$ of male students and $72.8 \%(\mathrm{~N}=150)$ of female students. The average age of participants was 16.06 $(s d=1.06)$.

\subsection{INSTRUMENTS AND PROCEDURE}

Consent was granted by the school principals prior to beginning a research study. In regular classes, students were asked to anonymously and voluntarily fill out the Users' Information Security Awareness Questionnaire (UISAQ) [2], the Consciousness Subscale from the International Personality Item Pool (IPIP) [14], and the Brief Self-Control Questionnaire [15].

The UISAQ consists of two parts with a total of 33 questions; some of the questions were adapted for secondary school students. The first part of the UISAQ consisted of 17 questions measuring computer users' potentially risky behavior (borrowing data, disclosing passwords, installing questionable programs, forgetting to log out of public IT systems, etc.). The second part of the questionnaire consisted of 16 questions measuring the level of users' information security knowledge and security awareness. In previous research, the UISAQ has proven to be a stable and valid measure of risky behavior and security awareness $[2,4]$.

All UISAQ subscales had satisfactory internal consistency coefficients; the first subscale $(k=5)$ had Cronbach $a=0.629$; the second $(k=6)$ had Cronbach $a=0.650$; the third $(k=6)$ had Cronbach $a=0.624$, the fourth $(k=5)$ had Cronbach $a=0.777$, the fifth $(k=5)$ had Cronbach $a=0.854$ and the sixth $(k=6)$ had Cronbach $a=0.765$. 
The consciousness subscale $(k=10)$ and the SelfControl Questionnaire $(k=13)$ showed satisfactory internal consistency; i.e., Cronbach $\mathrm{a}=.806$ and Cronbach $a=0.786$, respectively.

Students were also asked to answer some general data questions about themselves (age, gender), average time they spend on the Internet daily (in hours), and respond with either yes or no to the following two statements:

(1) My parents talked with me about the risks and dangers that may occur while using a computer or the Internet.

(2) My parents set certain rules or limits on me as to the use of a computer or the Internet.

Students were also briefly informed about the research before conducting the survey. It took 15 minutes to complete the questionnaires.

\section{RESULTS}

Data was analyzed by using the Statistical Package for the Social Sciences (SPSS 20).

\subsection{DESCRIPTIVE DATA ANALYSIS AND FACTOR ANALYSIS}

Descriptive analysis showed that $48 \%$ of adolescents spend on average more than 4 hours a day on the Internet, $47 \%$ of adolescents spend between 2 and 4 hours a day on the Internet and only $5 \%$ of adolescents spend less than 2 hours a day on the Internet. However, there is no gender difference in time spent online.

Almost a quarter of parents (24\%) never spoke to their child about the risks on the Internet and security awareness (compared to $76 \%$ of parents who did) and only a quarter (23\%) of parents set rules or limits on their child in terms of Internet usage (compared to $77 \%$ who did not).

Factor analysis of the UISAQ showed a three-factor structure of the first part of the questionnaire and a three-factor structure of the second part of the questionnaire. With the principal components method and Oblimin rotation, the $1^{\text {st }}$ factor of the $1^{\text {st }}$ part of the UISAQ accounted for $23.39 \%$ of total variance, the $2^{\text {nd }}$ factor $11.20 \%$ of total variance and the $3^{\text {rd }}$ factor $9.42 \%$ of total variance (a total of $44.02 \%$ of total variance has been explained). The $1^{\text {st }}$ factor of the $2^{\text {nd }}$ part of the UISAQ explained $22.10 \%$ of total variance, the $2^{\text {nd }}$ factor explained $17.09 \%$ of total variance and the $3^{\text {rd }}$ factor explained $15.63 \%$ of total variance (a total of $54.83 \%$ of total variance explained).

Distributions of UISAQ results are not normal (the Kolmogorov-Smirnov test was significant for all subscales), which was expected. Negatively asymmetrical distributions refer to borrowing data, risky behavior and data security variables, which suggests that students do not show much risky behavior (only some), they sometimes lend their data, but are not aware of possible data theft (low data security awareness).
Positively asymmetrical distributions refer to computer maintenance, proper data storage and belief in communication security variables, which suggests that students take care of computer maintenance, proper data storage but have low security awareness of information communication technology (believe that ICT is safe). These results (shown in Table 1) suggest that security awareness of adolescent is low and should be developed through educational programs and parental mediation.

Table 1. UISAQ descriptive data

\begin{tabular}{|c|c|c|c|c|}
\hline & Min & Max & M & Sd \\
\hline $\begin{array}{l}\text { Risky user } \\
\text { behavior }\end{array}$ & 1 & 5 & 1.87 & 0.63 \\
\hline $\begin{array}{l}\text { Computer } \\
\text { system } \\
\text { maintenance }\end{array}$ & 1 & 5 & 3.42 & 0.69 \\
\hline Borrowing data & 1 & 5 & 1.35 & 0.51 \\
\hline $\begin{array}{l}\text { Communication } \\
\text { security }\end{array}$ & 1 & 5 & 3.21 & 0.74 \\
\hline $\begin{array}{l}\text { Data security } \\
\text { awareness }\end{array}$ & 1 & 5 & 2.45 & 1.02 \\
\hline $\begin{array}{l}\text { Proper data } \\
\text { storage } \\
\text { awareness }\end{array}$ & 1 & 5 & 4.06 & 0.68 \\
\hline
\end{tabular}

Min $=$ minimal response for items on the subscale, Max = maximum response for items on the subscale, $\mathrm{M}=$ average response by item on the subscale; $\mathrm{Sd}=$ standard deviation

\subsection{UISAQ CORRELATES}

Results (Table 2) showed that there are statistically significant (low to moderate) correlations between consciousness and risky user behavior, borrowing data, computer maintenance and proper data storage. Also, there are statistically significant (low to moderate) correlations between self-control and risky behavior, borrowing data, computer maintenance and proper data storage. Personal traits influence risky user behavior and security awareness; students with more self-control and a higher level of consciousness (i.e., who are more responsible) show less risky behavior and more security awareness.

Time spent on the Internet is associated with selfcontrol and proper data storage awareness (correlations are low, but statistically significant). Adolescents who spend more time online are those with a lower level of self-control and a higher level of proper data storage awareness, which is in accordance with previous research showing that time spent online is associated with personality traits such as self-control $[2,9]$.

Results showed that there are statistically significant low to moderate correlations between subscales of the first part of the UISAQ; different types of risky behavior, borrowing personal data and computer maintenance. Those students who behave in a more risky manner 
also lend their data and maintain their computer systems less frequently. Also, those who think ICT is safe have low data security awareness and low proper data storage awareness. These results are in accordance with previous similar research establishing that various risky behaviors are mutually associated, as well as that there are different types of security awareness $[2,4,16]$.

Security awareness and risky behaviors are statistically significant, but they have a very weak negative correlation. Those students who have greater security awareness behave just slightly less risky. The nature of this very low correlation should be further investigated; the question arises as to why those students with higher levels of security awareness demonstrate only marginally more careful behavior. Since personality traits (consciousness and self-control) showed a significant correlation with user behavior in this research, some other personality traits (like neuroticism or extraversion) and users' motives for risky behavior should be considered in further research.

Table 2. Pearson correlation coefficient between different UISAQ subscales, consciousness, self-control and time spent on the Internet

\begin{tabular}{|c|c|c|c|c|c|c|c|c|c|}
\hline & 1 RB & $2 S M$ & 3 BD & $4 \mathrm{CS}$ & $5 \mathrm{DSA}$ & 6 PDS & $7 \mathrm{CON}$ & $8 \mathrm{SC}$ & $9 \mathrm{TI}$ \\
\hline $1 \mathrm{RB}$ & - & $-.152^{*}$ & $.509^{* *}$ & & & $-.407^{* *}$ & $-.271^{* *}$ & $-344^{* *}$ & \\
\hline $2 \mathrm{SM}$ & & - & $-.198^{* *}$ & $-.146^{*}$ & & $.314^{* *}$ & $.240^{* *}$ & $.173^{*}$ & \\
\hline 3 BD & & & - & & & $-.346^{* *}$ & $-.301^{* *}$ & $-.334^{* *}$ & \\
\hline $4 \mathrm{CS}$ & & & & - & & & & & \\
\hline 5 DSA & & & & & - & $.145^{*}$ & & & \\
\hline 6 PDS & & & & & & - & $.271^{* *}$ & $.202^{* *}$ & $.165^{*}$ \\
\hline $7 \mathrm{CON}$ & & & & & & & - & & \\
\hline $8 \mathrm{SC}$ & & & & & & & & - & $-.141 *$ \\
\hline $9 \mathrm{TI}$ & & & & & & & & & - \\
\hline
\end{tabular}

$\mathrm{RB}=$ risky user behavior, $\mathrm{SM}=$ system maintenance, $\mathrm{BD}=$ borrowing data, $\mathrm{CS}=$ communication security beliefs, DSA = data security awareness, PDS = proper data storage awareness, CON = consciousness, $\mathrm{SC}=$ self-control, $\mathrm{TI}=$ time spent on the Internet daily. ${ }^{* *} \mathrm{p}<0.01 ;{ }^{*} \mathrm{p}<0.01$

\subsection{AGE, GENDER AND PARENTAL MEDIATION}

There is no difference in either UISAQ subscale in the function of age, because age differences are small in this research, i.e., adolescents were $15-18$ years old. Further research should include both older (15-18 years old) and younger adolescents (11-14 years old).

Results showed that girls are more aware of security and privacy risks; they think there is a greater chance someone will steal their data $(t=2.658, p<0.01)$ and that computer system maintenance is more important $(t=3.021, p<0.01)$, but they do not behave more carefully than boys. These results are in line with some previous research results revealing that there are some gender differences in terms of security awareness; adult female participants are more security aware than adult male participants $[2,4]$.

Parents talk more about dangers on the Internet with girls than with boys $\left(X^{2}=15.4, p<0.01\right)$, but there is no difference in gender when it comes to rules parents set for their child. This result is in accordance with some previous research results showing that parents monitor girls' online activity more than boys' online activity [9, 12]. Those who parents talk with about the risks show less risky behavior $(t=10.0, p<0.01)$, rarely lend their data $(t=29.2, p<0.01)$ and consider proper data storage more important $(t=9.3, p<0.01)$, compared to those who parents never talk with about online security risks. However, there are no differences in terms of security awareness or risky behavior regarding the rules parents set for their children. These results are in accordance with the results of some other research studies [9, 11], which concluded that active parental mediation (talking with a child, being present when a child uses media, etc.) is crucial when it comes to protecting a child from negative media influence or online threats like cyberviolence.

This study came to an important conclusion that has a practical purpose - parental media mediation has an important impact on adolescents. Parents should openly discuss online content with their children more frequently, while exclusive bans will not increase children's ICT security awareness. In addition, parents who have older children, boys and children who spend more time online, should especially engage in active mediation.

\section{CONCLUSION}

The human factor has been found significant in the security chain. Different types of risky online behavior are positively correlated, so it is necessary to increase users' security awareness. However, users who are aware of the risks do not behave significantly more carefully and it would be useful to find out why this is the case. This research confirmed that some personality traits (consciousness and self-control) significantly influence users' behavior. Further research should include other personality traits and users' motives for risky behavior as well as a larger sample. 
The Internet poses a risk to every user's security and privacy, especially to children's and adolescents' security because they are not aware of these threats. Adolescents spend a lot of time online; half of them even more than 4 hours a day. This research showed that parental mediation is crucial in promoting security awareness of younger population. However, a lot of parents never talked about security awareness or rules set for their children in relation to the Internet usage. Parents should focus on boys' online activity more than they do currently. We need more research into parental mediation strategies that are more and the ones that are less efficient in order to successfully advise parents on how to monitor their child's IT use. This research showed that talking to a child is more efficient than setting rules.

\section{REFERENCES:}

[1] M. Ybarra, K. Mitchell, "Prevalence \& frequency of Internet harassment instigation: Look at Cyberbullying", Youth Violence and Juvenile Justice, Vol. 4, No. 2, 2007, pp. 148-169.

[2] T. Velki, K. Šolić, K. Nenadić, “Razvoj i validacija Upitnika znanja i rizičnog ponašanja korisnika informacijskog sustava (UZPK)", Psihologijske teme, Vol. 24, No. 3, 2015, pp. 401-424.

[3] S. Livingstone, M. Bober, "Regulating the internet at home: Contrasting the perspectives of children and parents", Digital Generations, pp. 93-113, Mahwah, NJ, Erlbaum, 2006.

[4] T. Velki, K. Solic, V. Gorjanac, K. Nenadic, "Empirical study on the risky behavior and security awareness among secondary school- validation and preliminary results", Proceedings of the 40th International Convention on Information and Communication Technology, Electronics and Microelectronics, Opatija, Croatia, 22-26 May 2017, pp.1280-1284.

[5] G. Rakić-Bajić, V. Hedrih, "Prekomjerna upotreba interneta, zadovoljstvo životom i osobine ličnosti", Suvremena psihologija, Vol. 15, No.1, 2012, pp. 119-131.

[6] K. Karl, J. Peluchette, C. Schlaegel, "Who's posting Facebook faux-pas? A cross-cultural examination of personality differences", International Journal of Selection and Assessment, Vol. 18, No. 2, 2010, pp. 174-186.
[7] G. E. Higgins, B. D. Fell, A. L. Wilson, “Digital piracy: Assessing the contributions of an integrated selfcontrol theory and social learning theory using structural equation modeling", Criminal Justice Studies, Vol. 19, No.1, 2006, pp. 3-22.

[8] M. A. Sasse, S. Brostoffand, D. Weirich, "Transforming the 'weakest link' - a human/ computer interaction approach to usable and effective security", BT Technology Journal, Vol. 19, No. 3, 2001, pp. 122-131.

[9] S. Livingstone, L. Haddon, A. Görzig, K. Ólafsson, "Risks and safety on the internet: the perspective of European children: full findings and policy implications from the EU Kids Online survey of 9-16 year olds and their parents in 25 countries", Deliverable D4, EU Kids Online Network, London, UK, 2011.

[10] M. Đuraković, I. Klasnić, “Povezanost školskog uspjeha i rizičnih ponašanja srednjoškolaca na internetu", Napredak, Vol. 157, No. 3, 2016, pp. 263-281.

[11] S. Livingstone, E. J. Helsper, "Parental mediation of children's internet use", Journal of Broadcasting \& Electronic Media, Vol. 52, No. 4, 2008, pp. 581-599.

[12] I. Lagator, "The relation between parental supervision and conduct on the internet", Josip Juraj Strossmayer University of Osijek, Faculty of Humanities and Social Sciences, Master's Thesis, 2008 (in Croatian)

[13] E. Brčić, "Loneliness and problematic Internet use among high school and university students", University of Zadar, Department of Psychology, Master's Thesis, 2016 (in Croatian)

[14] B. Mlačić, L. R. Goldberg, "An Analysis of CrossCultural Personality Inventory: The IPIP Big-Five Factor Markers in Croatia", Journal of Personality Assessment, Vol. 88, No. 2, 2007, pp. 168-177.

[15] J. P. Tangney, R. F. Baumeister, A. L. Boone, “High selfcontrol predicts good adjustment, less pathology, better grades, and interpersonal success", Journal of Personality, Vol. 72, No. 2, 2004, pp. 271-322.

[16] L. Vejmelka, N. Strabić, M. Jazvo, “Online aktivnosti i rizična ponašanja adolescenata $u$ virtualnom okruženju", Društvena istraživanja, Vol. 26, No.1, 2017, pp. 59-78. 